\title{
The Design of Flexible Furniture for the New Generation Offices
}

\author{
Didem Bedük Tuncel*, Hande Zeynep Kayan \\ Department of Interior Architecture, Faculty of Architecture, Mimar Sinan Fine Arts University, İstanbul, Turkey
}

Copyright $\subset 2018$ by authors, all rights reserved. Authors agree that this article remains permanently open access under the terms of the Creative Commons Attribution License 4.0 International License

\begin{abstract}
The technological developments in every extent cause the office interiors to change, the furniture to be updated. This situation brings along new concepts in working spaces and furniture design. Because the changing activities require different technologies in the offices that consist of individuals coming together for the same purposes, especially the $\mathrm{Y}$ generation born between 1981-2000, raised in the 4th Industrial Revolution era has an important effect on workplace designs. In this era where modern information and mobile technologies come into prominence; the family and social life culture is changing rapidly and man power is slowly getting behind robotic-smart systems. The $\mathrm{Y}$ generation has different choices from their clothes to working hours, from their thinking to the way they work; so they demand flexibility in every aspect in their offices. This situation affects the use of technology, and working systems more and more each day causing us to rethink the working areas and how we use the office furniture.
\end{abstract}

Keywords Office Furniture, Flexibility, User Needs

\section{Introduction}

This paper explores the new office furniture that has changed in the new era in a more flexible way to fit the needs of changing technologies and new generation users. Our objective is to find out the reasons for the need of flexibility in the offices and comment on their reflections in contemporary furniture examples. By doing this, we aim to discover the bond between technology, working organizations, user needs, social and cultural changes and flexible furniture. In order to understand this link, we must define office and flexibility concepts first.

Office is a space where the workers interact constantly within the framework of the task. It is also a space that creates a setting for several social relations to happen as a result of different hierarchical structures. Offices are not only collective spaces used by managers and workers; they also support the work physically, socially, psychologically and facilitate the process of work [1]. On the other hand, office furniture is an ergonomic product that has a place in every area of working life, serves the social and cultural necessities directly related with human life quality.

In all of these definitions, we have to point out that technological developments are on the foreground in the design of adaptable spaces and furniture to the user's requirements. In the light of this, we can define office as; a dynamic environment created by interaction; changing, renewing itself by technological impact with intense flow of information. Especially when the user is unknown, none of the designs created for office spaces can fit the work done there. In this case 'flexibility' is the keyword.

Flexibility is a sustainable solution that harbours conditions of different users and their requests under the influence of changing organizations and developing technologies. Flexibility is a concept that enables the user to work where they want, removes the limitations and supports not only the comfort of the body, but the mind also.

\section{Changes in the Office Concept}

Throughout history, we can see office interiors and furniture has changed due to a lot of spatial and intellectual reasons. Some of these are; changes in working organizations, the sociocultural structure and needs of users, economical factors, the form of the building, the plan scheme or how/how much the technological developments are used in the corporation. In addition to these, adaptations of different generations to new technologies, working life and lifestyle affect the usage patterns of the office designs, their needs, their expectations and the equipment selection.

The X generation that was born between the years 1965 and 1979 have caught up with the computer technologies even though they were not born to it. In office life, they like to be given responsibility and want more privacy and 
personalization. In this era, alternative office designs were seen where users can use the office spaces and time in new ways.

The Y generation on the other hand were born into computer technology and have the ability to use it masterfully. For them, office is the space where you are. The need to be in an office building or close together with co-workers is not necessary. Flexible working hours with flexible furniture and spaces are needed for the fast paced working organizations. Because then the working hours will be more efficient. For example in B. Lays' new office in Bucharest; no employee has its own desk, everybody should be able to work anywhere, depending on their task. (Figure.1)
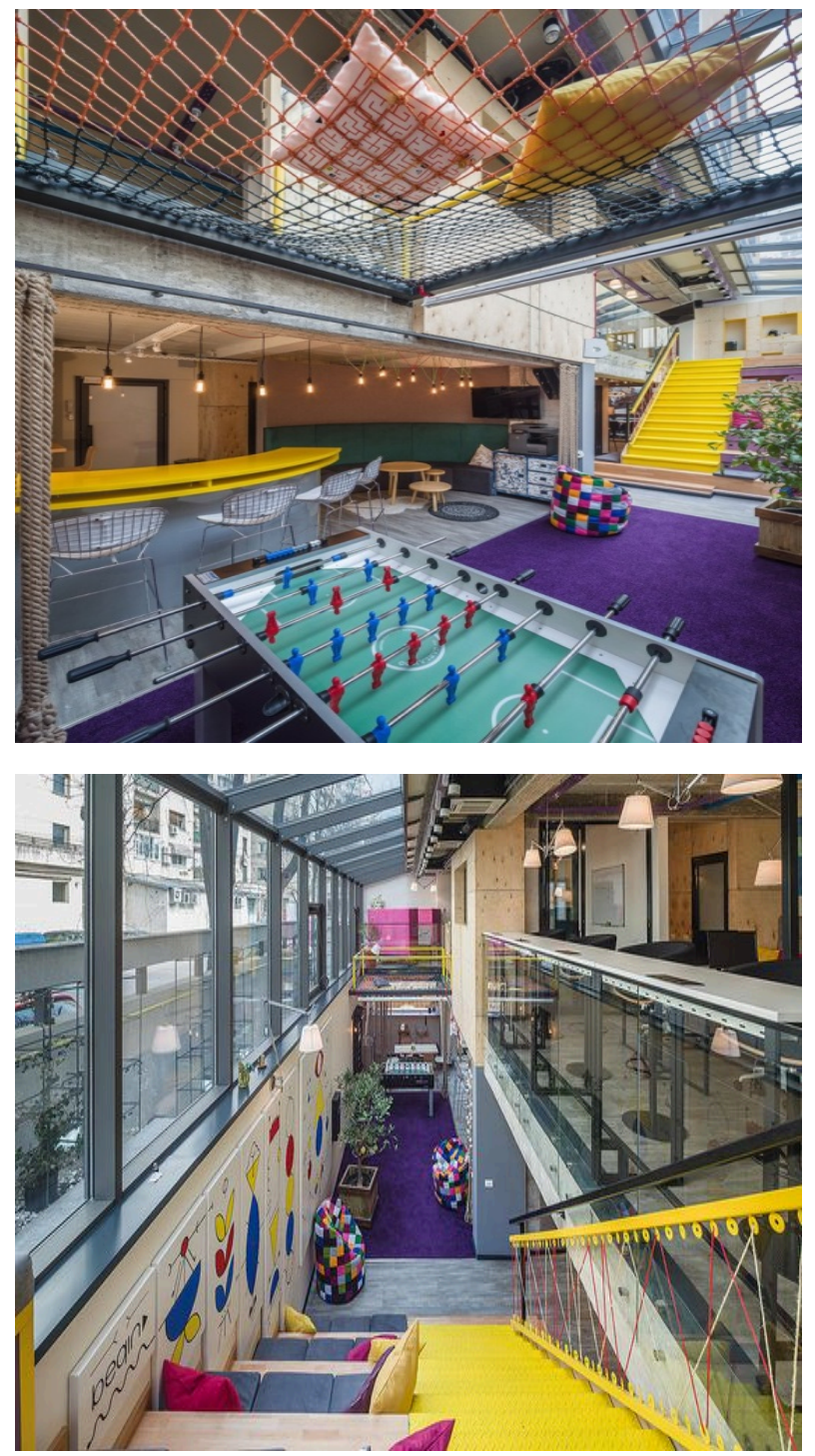

https://blog.eoffice.net/2015/04/an-inspiring-interview-with-dotka-the-cr eatives-behind-b-lays-new-office-in-bucharest-romania/

Figure 1. B. Lays, in Bucharest, Romania

\subsection{Work Organization}

The person/worker who is bound to spend a portion of his lifetime in the office to reach his living standards has been seen to go through changes in working area requirements within time. The administrational changes at the offices, customer participation, business potential, economical opportunities, cause the need for adaptability to changing situations. This leads to new balances between work and home life. As the variables like the quality, the style, the management, the working team of the job changes; the space and the furniture serving it takes shape accordingly.

New technology brings possibilities of uninterrupted communication, which leads to a more connected spatial design that has furniture designed with a continuous structure. Superdesk is an example of this continuity that is realized not only by the possibilities of material technology but the support of computer programs dissolving the boundaries of design (Figure.2). In here the users work on the same surface under the same circumstances. "Clive Wilkinson Architects (CWA) used the 3D-modeling software Rhinoceros and Revit to achieve the desk's geometry. The desk measures 1,100 feet long and 11-1/2 feet across at its widest point. An embedded utility tray makes power and data cables accessible along the length of the desk." [2]
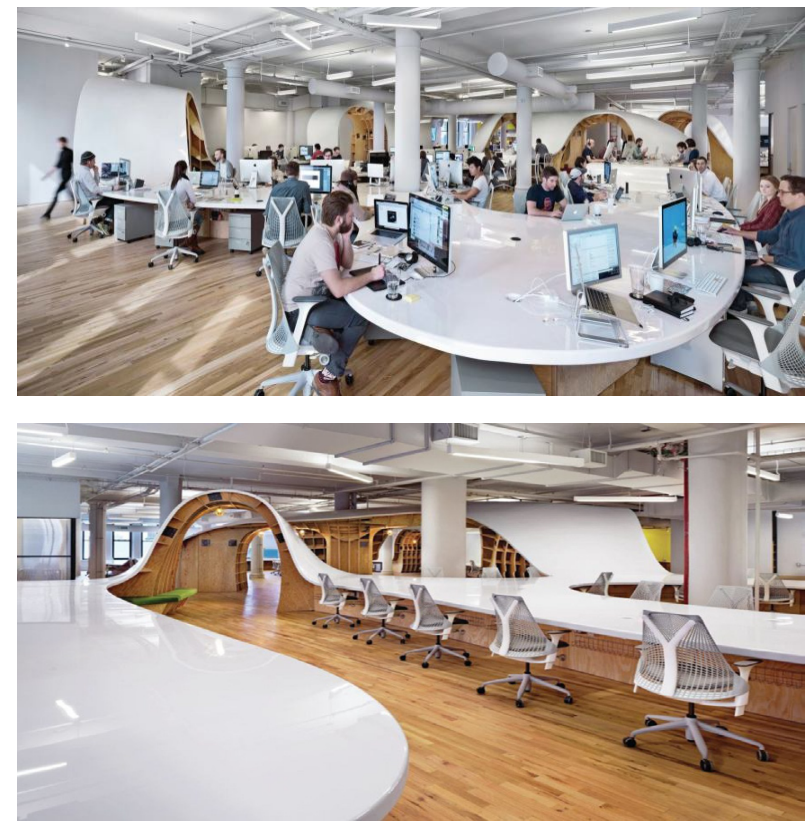

http://www.architectmagazine.com/technology/detail/innovative-detail-t he-superdesk-at-the-barbarian-group-office o

Figure 2. Superdesk, Barbarian Group Office, Clive Wilkinson Architects

The acceleration of developments in technology has an enormous effect on the employees and management. It brings the necessity to handle the working environment all over again because of changes in the way we look at supervision mechanisms or hierarchy between workers or the flexibility in working hours. If we have fixtures with enough technology for the users, besides correct spatial organization; the work process will be faster and will 
develop continuously.

As an example, (Figure 3) Clive Wilkinson Architects working with DEGW designed the Disney Store Headquarters by colourful blocks that become both walls and furniture according to their need. The blocks are made of foam and they become the walls of the Conference Room. The walls also transform into a seating system for meetings of 200 people. [3]
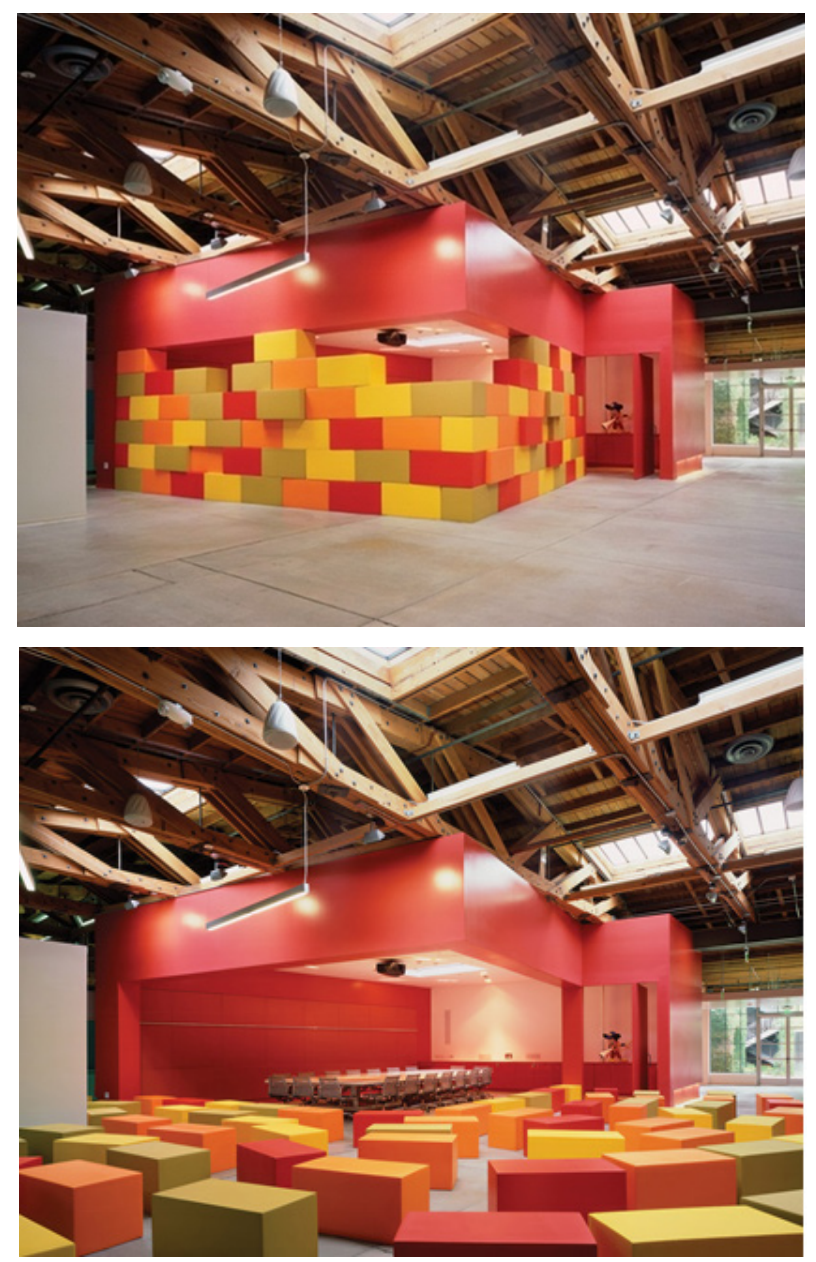

http://www.clivewilkinson.com/portfolio_page/disney-store-headquarter

Figure 3. The Disney Store Headquarters, Clive Wilkinson Architects, California

\subsection{User Needs}

Customization or personalization is an important factor in office spaces today. The user is motivated and office life is positively affected by the flexible workstations designed to fit his/her characteristics. Especially The Y generation who like to show their identity; be differentiated from their environment and express themselves in their own space. Sharon Marston states that people are faced with a world of choices. "I believe that this is a positive step, for people are now offered the options of different colours, materials, sizes, functions and price variations. As humans, we consider ourselves individuals and like to assert our different tastes. Our decisions on the objects we surround ourselves with, define part of who we are and provide us with identity through difference" [4]. This approach is seen in another designer Karim Rashid who says "products must deal with emotional ground and increase the popular imagination and experience. Diversity, variance, multiplicity and change are part of every whole construct." [4]

Many methods of alternative uses are applied in furniture designs linked with the workers' need to create a personal space for themselves under the same roof or around the same table. The Collect series (Figure.4) designed in this understanding; "include writing boards, pen shelves, mirrors, coat hangers and hooks that are all easy to hang on the screen. The accessories are made out of ash wood and are available in natural colour, as well as black- and white-stained." [5]
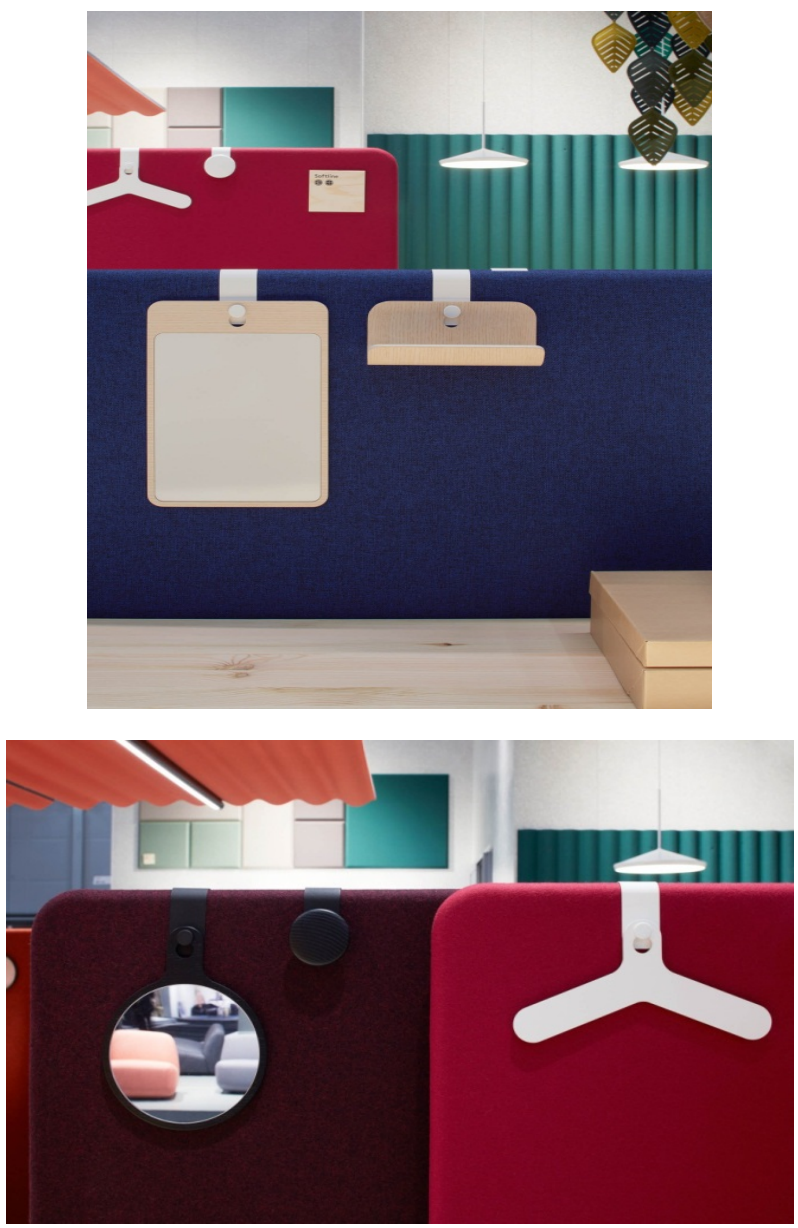

https://abstracta.se/product/collect/

Figure 4. Nina Jobs, Collect For Abstracta

Offices are now under the severe influence of technology. The use of electronic devices has increased and sharing of information has become widespread. As a consequence, the priorities and needs have changed towards flexible furniture systems that provide alternative uses of space. These furniture systems are preferred 
because of their modular pieces that can be put together differently according to the need and the identity of users. The important point in forming the modules is to figure out the requirements and the location correctly; while solving the details about lightness, strength, movability and transformability of the material.

In the spaces where flexibility is an important factor, sustainability is provided by the use of neutral surfaces divided or added according to the number of users. With a modular piece of partition, working surfaces can serve different users at the same time.

\subsection{Social and Cultural Changes}

Work culture is developing according to globalized business world, global administration systems and fluctuations in economy and politics [6]. These factors change the working culture, thus change the working environment. To enhance performance of employees, a lot of space use approaches are developed. As our vision of workstations change, we see workplaces with minimum hierarchy, maximum autocontrol and more people in communication and interaction. To make the $\mathrm{Y}$ generation comfortable and happy at work; designers can use changeable accessories for personalization. There are wide range of form and material for the furniture to be used alternatively as the user wishes. Modules can be added to the workstation to make them work individually; have meetings; have a social gathering or take a break. This can be done by adding, turning, subtracting, sliding, lifting the modules to fit the function (Figure 5).
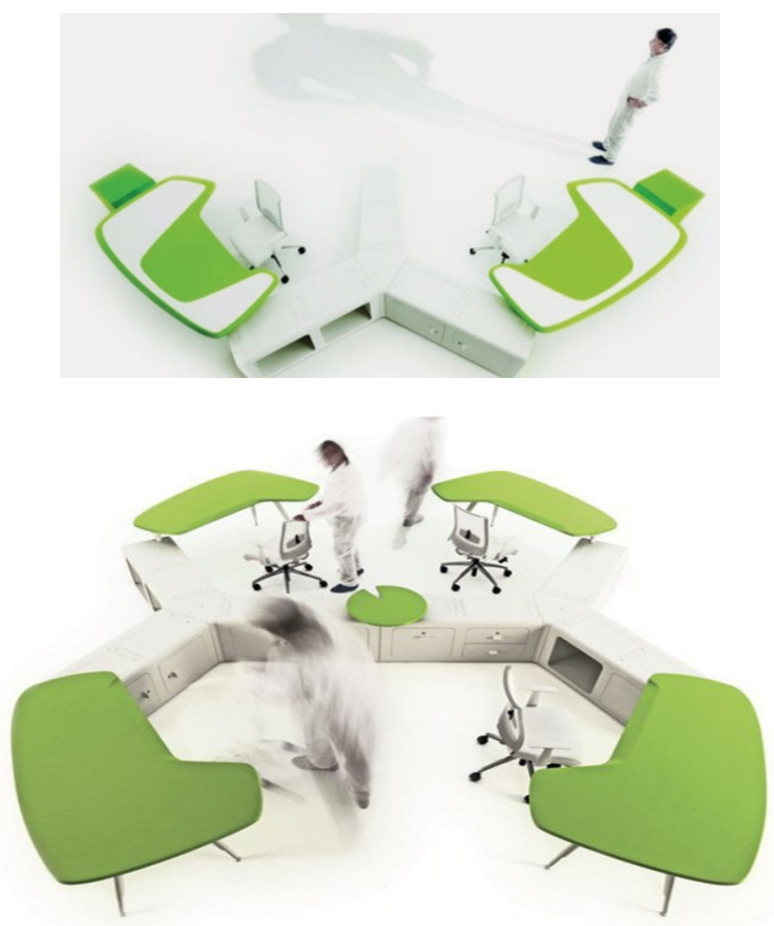

http://www.designed.rs/d-report/milano_2010/tecno_spa___entering_10s

Figure 5. Tecno Spa, Pierandrei Associati and Betaunopuntozero
There are also different working organizations developed for the new world. Collective offices that are shared spaces have come up from the needs of free-lance working people mostly. These out of office methods are generally called "ready office' or 'co-working offices" that can be rented by appointment. They are "cooperative and flexible working systems that are self-driven and depend on sharing of resources.' The choice of collective offices have increased since communication, interaction and sharing, flexible working and experiencing different spaces have become important especially for the Y generation.

As an example for, co-working office Kolektif House (Figure.6), gives reservations for a chosen table, room or surface. At the same time there is the idea of individual office in the meeting rooms or group working areas. Generally there is no special unit for users but a renting system that brings a space open to creativity and different experiences contrary to the conventional systems. In the neutral spaces left; there are seminers, movie screenings, shows, product launches done by using flexible furniture. This leads to efficiency and increased productivity; increased collaboration; improved cost management and heightened level of security.
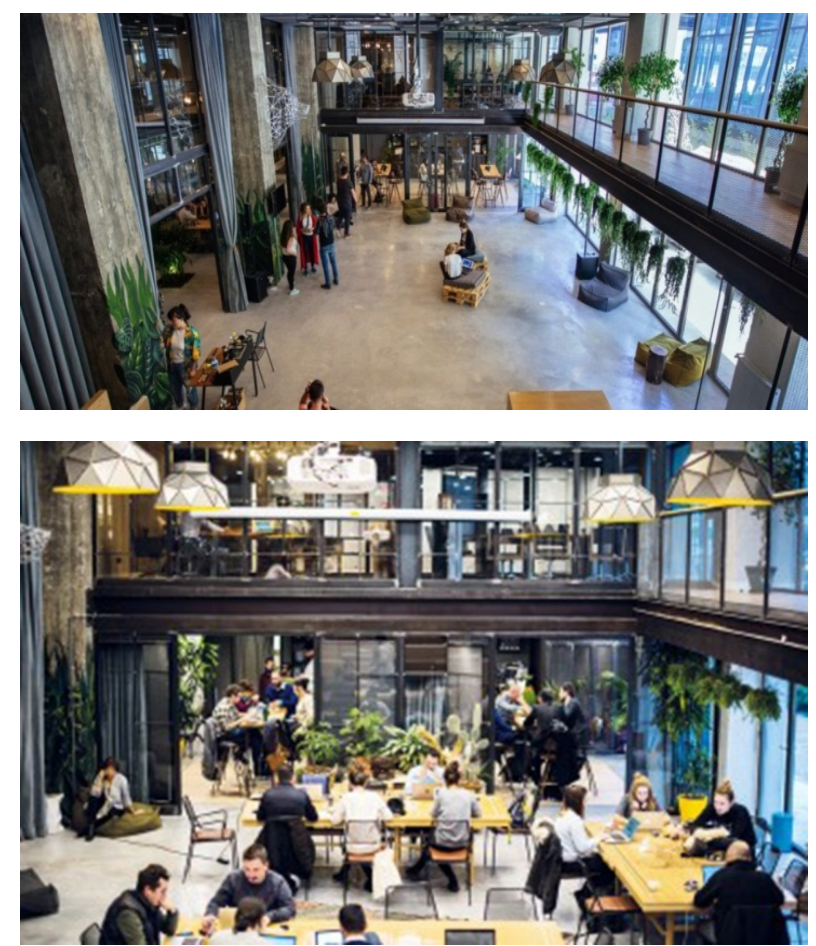

http://www.kolektifhouse.co/sanayi-ofis/

Figure 6. Kollektif House, Sanayi, Levent, İstanbul

\section{New Technologies and Office Furniture}

Discovering a new material means a very intense and accurate study in formation of structure which free-stands 
the design and accomplish it. "Often with the introduction of new manufacturing techniques and materials, particularly in $19^{\text {th }}, 20^{\text {th }}$ and $21^{\text {st }}$ centuries, it was furniture that first used new technological possibilities." Use of technologies in furniture design especially developed after World War II. The metal and wood structures were replaced by plastic, paper and textile materials very often. The new era has brought to us, composite materials and computer aided production that allows the product to become more flexible and multifunctional. [7] Computer aided design and internet also paved the way of rapidly spreading new ideas where concept of flexibility has become the center of attention. This concept is supported by changeability and mobility that new technology brought to us.

"Today a wide range of technologies developed in recent years is available to furniture designers and makers, resulting in lots of new possibilities, making it a very exciting time to be involved in furniture" [8]. For Karim Rachid, inspiration comes from here: "I believe that the new objects that shape our lives are trans-conceptual, multicultural hybrids, objects that can exist anywhere in different contexts, that are natural and synthetic, that are inspired through telecommunications, information, entertainment and behaviour." [4]

So with this inspiration, while designing furniture for offices; we must investigate the smart systems, the new materials, how they are produced and find a way to make the offices more efficient. With today's technology that dissolves boundaries leading to information and communication; flexible furniture becomes the answer for offices because it adapts to changing situations and innovations.

\subsection{Material and Production Technologies}

Along with the developments in the field of material technology, it has become possible to apply many different approaches in furniture designs. The material is the first perceived surface that surrounds the furniture when viewed from the outside. Therefore, in the structures formed by the right material selected according to its space, function and strength; furniture designs can be freely realized associated with the diversity in production techniques since the industrial revolution.

The use of digital technology, both as a means of time gain and as a form of freedom is supported by the construction methods like cutting, mowing, shaping, reaction injection molding (RIM), polyurethane resin (PUR), ... etc. to make great steps in adapting the material to the furniture.

The use of computer affects furniture types structurally by making design and production of complicated geometries easy. Forms that could not be produced because of not having an appropriate technique before could be produced in a short time. "As a result of developing technologies new synthetic materials are produced on laboratory environment. These new products help a lot of design problems. Digital production machines, computer technologies, 3 dimensional CAD modelling programs, new synthetic and smart materials helped designers and producers to realize their designs." [9]

Materials are now more stronger, more harder, more lighter, with better isolation or transparent. Nanotechnology has the aim of guiding the atoms and molecules to make the material have the intended shape. Smart materials can send each other messages, information, sound, light with fiber lines connected by way of probes [10] "They can spontaneously change their physical properties-shape, conductivity, color, viscoelasticity, etc. in response to a natural or manual trigger such as a change in temperature, the presence of a magnetic or electrical field, or the application of stress. In short, the material responds to an external stimulus. Shape memory alloys are programmable metal alloys which can assume a different shape under certain physical stimuli, and return to their initial shape when the stimulus is removed." [11]

As technology develops, innovative acoustical products are often seen especially in offices. In an open office, the most important factor for acoustics is speech privacy. In order to maintain a proper environment for doing business, talking on the phone or having face to face meetings; an office worker needs an isolated space. Acoustic surfaces like ceilings and walls are not always enough for speech privacy. Designers have thought about this problem and designed furniture with sound absorbent qualities. These are mostly modular furniture with multi-functional qualities like being a partition and storage element at the same time while absorbing unwanted sounds. Today, instead of using wood or steel structure with textile, gypsum or metal panels on top; we are using polyester fiber structure with acoustic panels or 3D acoustical textile. [12]

Ecology is also a technological subject today. Technology companies have been increasingly moving to green product designs where they are using reduced amounts of heavy metals and other toxic materials. Also by incorporating more recyclable components such as composite materials with natural resins; furniture can be ecological.

Composites have become increasingly popular because of their multi-functional qualities. Carbon fibre is becoming an increasingly popular material for furniture design, due to its light weight relative to its high strength. Fibres can be used in many ways like knitting and braiding to have different forms. The rigidity of the fibers are maintained by coating or immersing them in resins of different kinds like epoxy, polyester or polyurethane. Each of the resins gives them a different property like toughness or flexibility. [12]

\subsection{Information, Telecommunication and Computer Technologies}

We have come a long way since the first Industrial 
Revolution that used steam power for production. Since then, the steps until today encompasses a mass production revolution with electric power to automated production revolution of electronics and information technology. Today, a new one is coming up which is the digital revolution. "It is characterized by a fusion of technologies and is blurring the lines between the physical, digital and biological spheres" [13]. The Fourth Industrial Revolution is a new concept which relates to the advancement in fields such as artificial intelligence, robotics, nanotechnology, 3-D printing and biotechnology. It is believed that these once disjointed areas have now reached a stage where their influence will cause widespread disruption and workplace change.

Towards a different working model in offices using time and space with efficiency; requires appropriate technology and appropriate building infrastructures. Information and communication technologies have brought advantages in our lives that provide space-user-worker relations to be handled in a different way. Especially with mobile technologies, we have to think about working in any place, the advantage of fast access and transport and fast flow of information. Sharing and having the data at the right time means that we do not need to be sitting at the office all day; on the contrary we must interact, communicate more with the work groups. The important thing is adaptability of our environment and equipment; especially the details to increase productivity.

The traditional office doesn't exist anymore. Cloud services and Wi-Fi networks have made work independent of place and time. People work temporarily at their own offices, from home, in video conferences, on business trips or at subsidiaries' offices. The activity-based office is the new way of working. Many designers have foreseen that in the future, surfaces will be actively used in the office spaces. Today; smart boards, interactive tables, interwall, holographic screen are some of the examples of these surfaces (Figure.7). Holographic screen is a two dimensional display technology that uses coated glass media for the projection surface of a video projector. It gives us multi-surfaces to work on and blends in the interior because of its transparency.

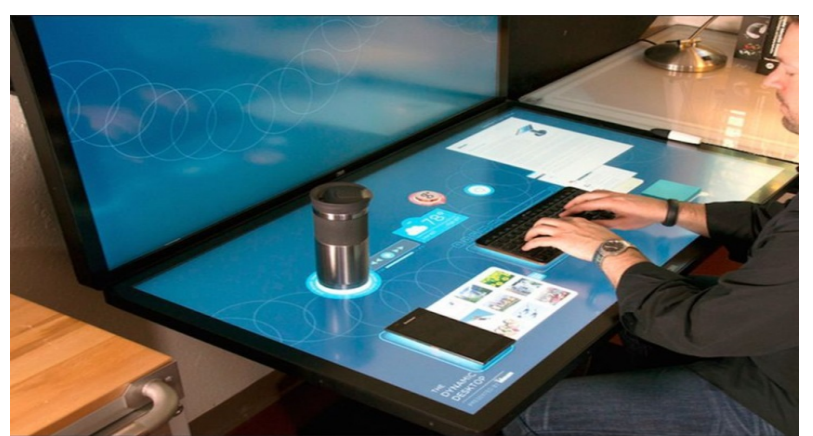

http://moveableonline.com/blog/2014/09/24/interaction-interfaces-tomor row-future-ui-ux/

Figure 7. Interaction desk
The transparency of the projection surfaces leads to creative solutions for information preparation: interactive elements with touch or gesture control broaden the scope of use.

Apart from these surfaces, virtual space is one of the most important technological developments that people can get information from. They interact with the space with virtual reality goggles. This interaction is done with a user interface.

\section{New Office Furniture}

Furniture has taken an important role by nano-technological potential in human-environment interactions. We can see extraordinary solutions with the last changes in the structural frame. Below are some examples of new generation office furniture that are created to have flexible properties.

\subsection{Build}
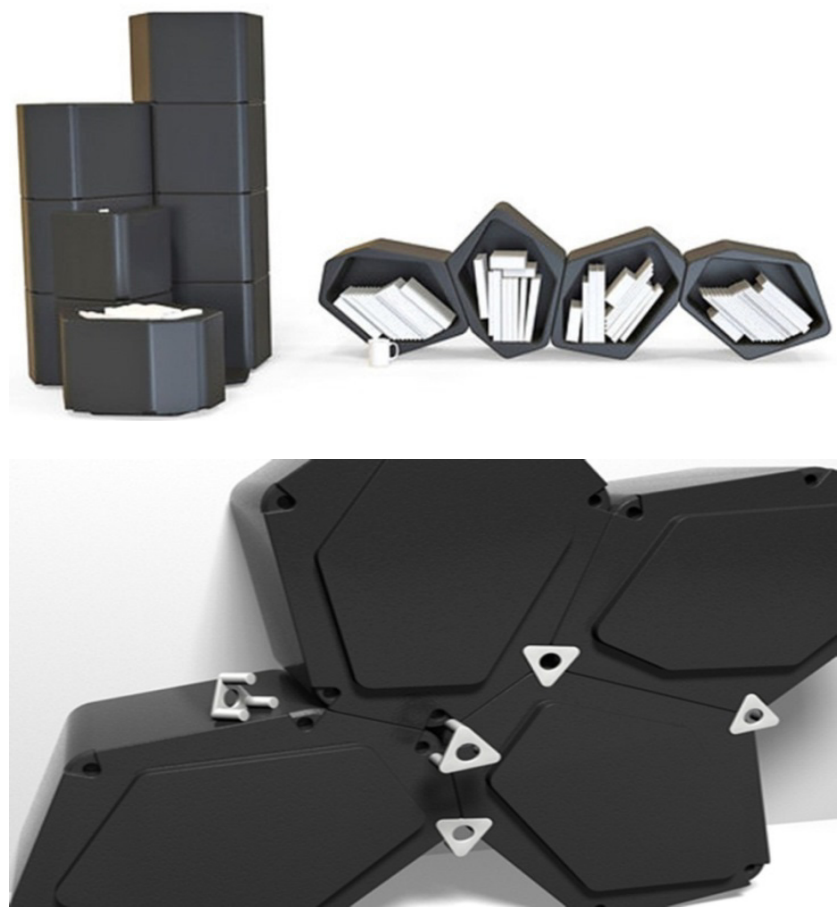

https://www.dezeen.com/2013/07/21/build-by-jack-godfrey-wood-and-to $\mathrm{m}$-ballhatchet-for-movisi/

Figure 8. Build, Jack Godrey Wood and Tom Ballhatchet

'Build' is an example for modular systems; it is a storage element produced by moulding of plastic material, put together by connection pieces. The characteristics of the system are to become flexible enough to be a seating element, a box to carry, a partition in need; and to be lightweight enough to be carried. (Figure 8) 


\subsection{Molo}

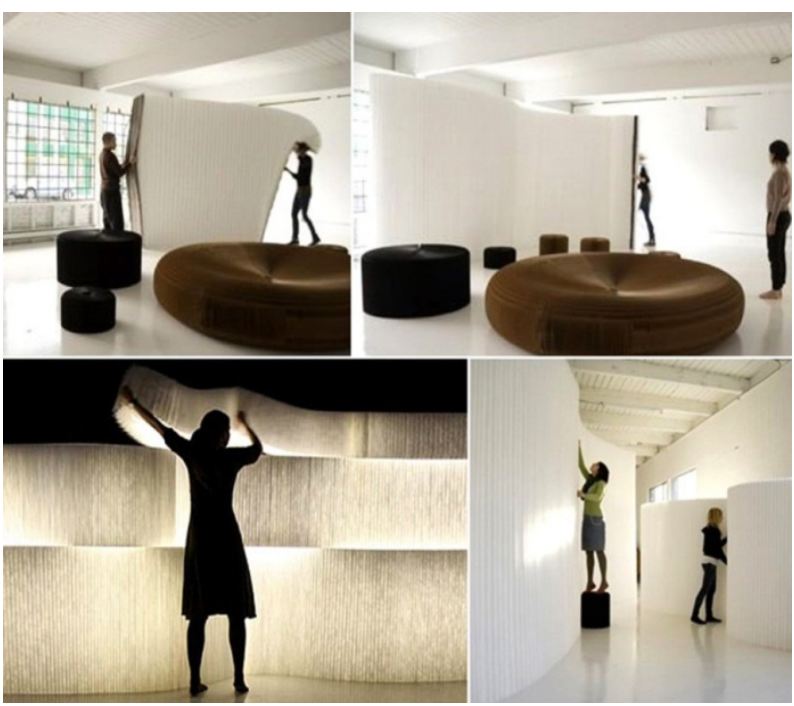

https://www.molostore.com/product-softwall-softblock

Figure 9. Softwall, Molo, Stephanie Forsythe and Todd MacAllen

Molo (Figure 9); is a flexible office furniture made from natural brown paper and white or black textile, which can be decomposed and assembled or extended to be used in any dimension or shape; which can become transparent or opaque. It may be used as a seating element, partition or work surface according to the need. Any softwall or softblock element can expand to a maximum of 4.5 meters, or to shorter lengths to suit particular occasions, and the material is light for easy use.

\subsection{Kivo}
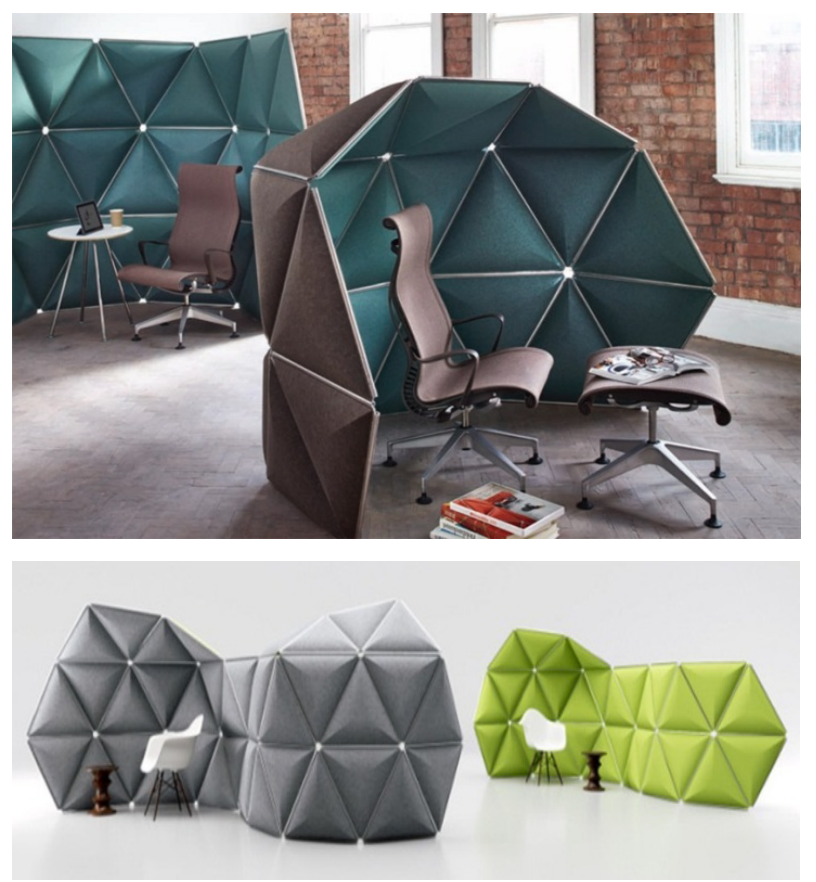

http://www.hermanmiller.com/content/hermanmiller/apac/en_apc/home/ design-resources/images.html?text=Herman\%20Miller:Products/Kivo

Figure 10. Kivo, Alexander Lorenz
Kivo, (Figure 10) is a workplace partition system designed exclusively for Herman Miller by Alexander Lorenz. The frame is composed of polished steel that encloses felt tiles. These triangular modules come together to form a space to work for better concentration with the sound absorptive effect of felt. Or they can meet up and collaborate easily with the help of flexible system. [14]

\subsection{Nest Shelf}
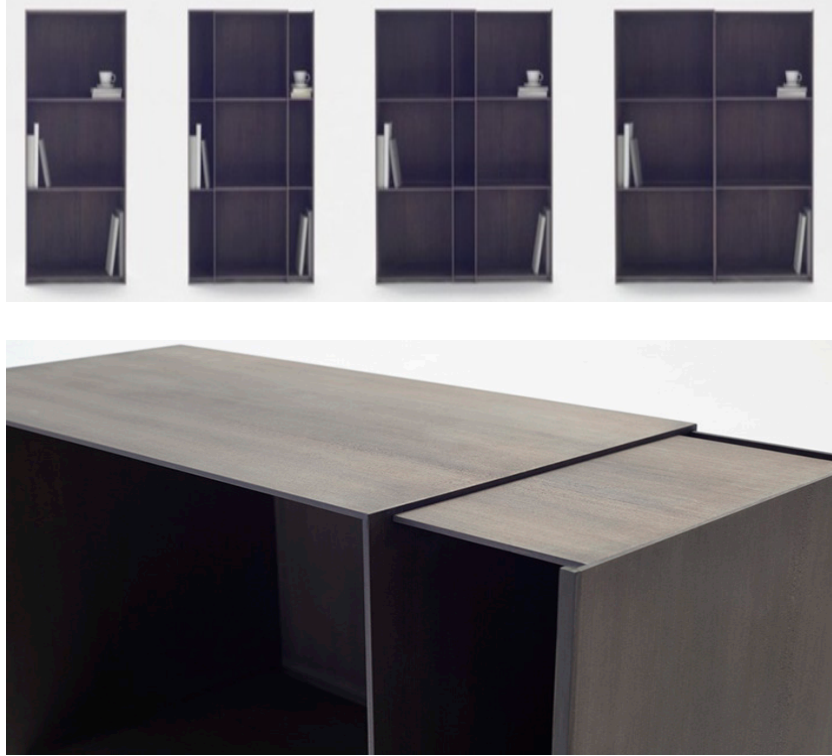

http://www.nendo.jp/en/works/nest-shelf/

Figure 11. Nest Shelf, Kris Lamba, Thomas Feichtner and Michael Sodeau Nendo, London Design Festival

The use of light but strong material with nanotechnology, which is one of the important developments in material technology, brings with it different alternatives and flexibility in storage elements. It is possible to use flexible office furniture, which can be increased in volume depending on the need instead of fixed and limited amount of storage.

"In the Nest shelves (Figure.11), the thinner expandable portion is hidden within the outer shelving layer, and assembled in a way that allows it to easily slide out when pulled. Vertical partitions are made from 3.7-millimetre carbon fibre, while horizontal elements comprise a honeycomb material made from synthetic fibres that is sandwiched between carbon-fibre layers. All the surfaces are covered in a wooden larch veneer" [15]

\subsection{The Gaia Workstation}

In offices where empty / neutral / open spaces are offered to the service of users and flexibility is supported, it is possible to work at any desired point by creating modules independent from the shell with the developing mobile 
technologies. Gaia is an office module designed with this approach.

"Gaia is a furniture (Figure.12); concept tailored for future office landscapes. Gaia's modular concept can easily be customized for different needs in an open office landscape and was engineered with focus on assembly and disassembly." Gaia's versatility may be the most appealing part. The various seating, organization and lighting options make it easy to create your ideal creative habitat. [16]
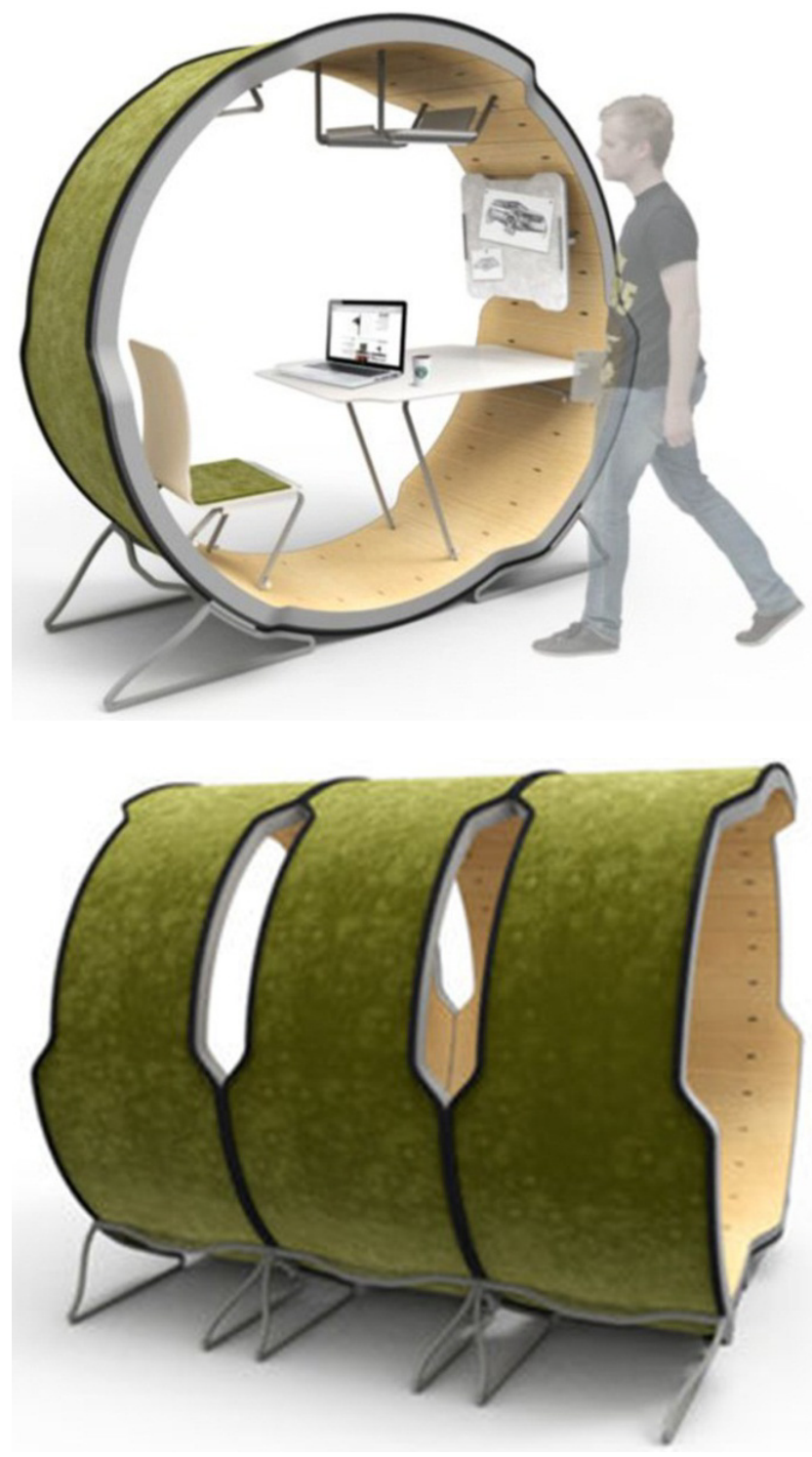

http://www.trendhunter.com/trends/gaia-workstation

Figure 12. The Gaia Workstation, David Bruér

\subsection{Scale, Flexible and Modular Acoustic Partition System}
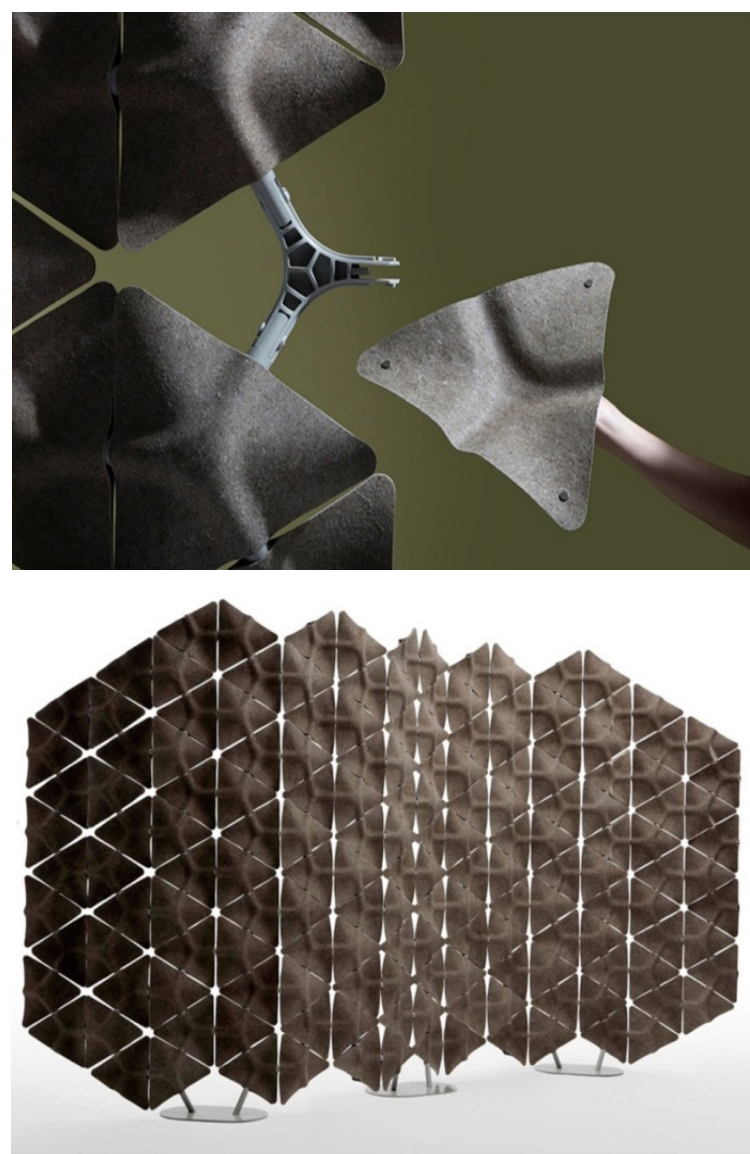

https://www.designboom.com/design/benjamin-hubert-layer-design-scal e-modular-acoustic-partition-system-12-04-2015/

Figure 13. Scale, Benjamin Hubert

Especially in open-plan offices, based on project-based changes in the number of employees; a flexible design is done in order to adapt spaces to changing situations. Modularity is supported by paying attention to the fact that the selected materials are particularly light and can provide solutions to the acoustic problem. According to Scale designer Benjamin Hubert; “ composed of pressed recycled hemp acoustic tiles, which clip onto an injection moulded recyclable ABS framework mounted onto aluminium, 'scale' (Figure.13) is not only produced from sustainable materials, but can adapt to the needs of a commercial interior over time. for example, it is ideal for a workplace growing and shrinking, that requires flexible work and break-out areas as teams are created and dissolved" [17] 


\subsection{Cega}
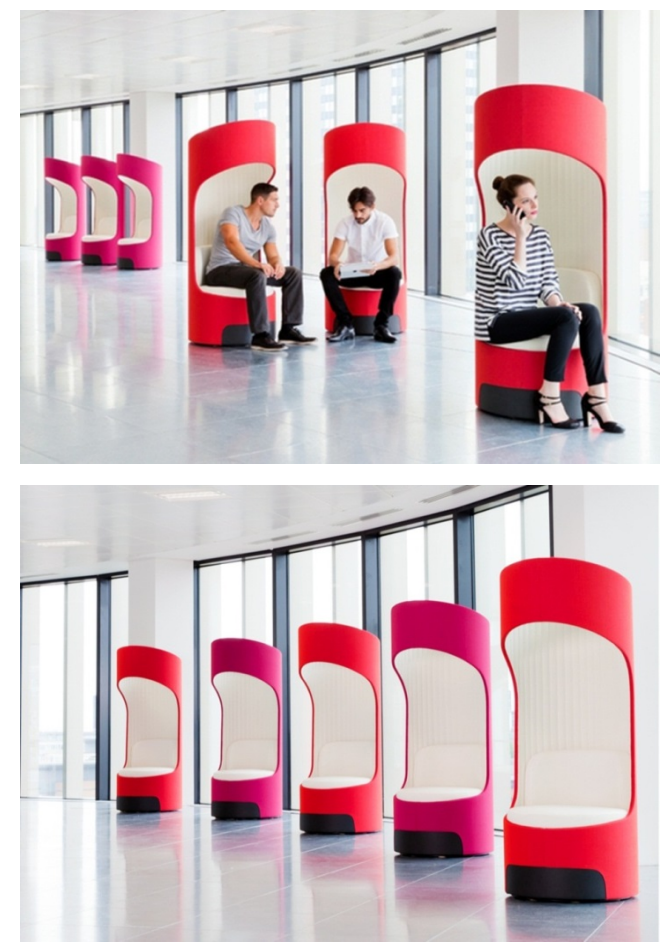

http://www.boss-design.co.uk/breakoutandupholstery/p/6/desc/cega/

Figure 14. Cega, Boss Design Group

Cega (Figure 14) is made for the modern working environment to enhance privacy. Special phone calls or meetings can be made in this sound absorbing unit. It also reduces peripheral vision and external noise for concentration while allowing light to pass from the open top structure.

\subsection{Nomado}

Nomado (Figure 15), is an example of multi-functional unit that acts as desk system and a partition wall. It can be used in dynamic offices that have a flexible organization or home-offices. The electric outlets and task lighting are integrated in the design. This compact mobile unit has a worktop and when it's folded flat, it turns into a wall separator and storage space.

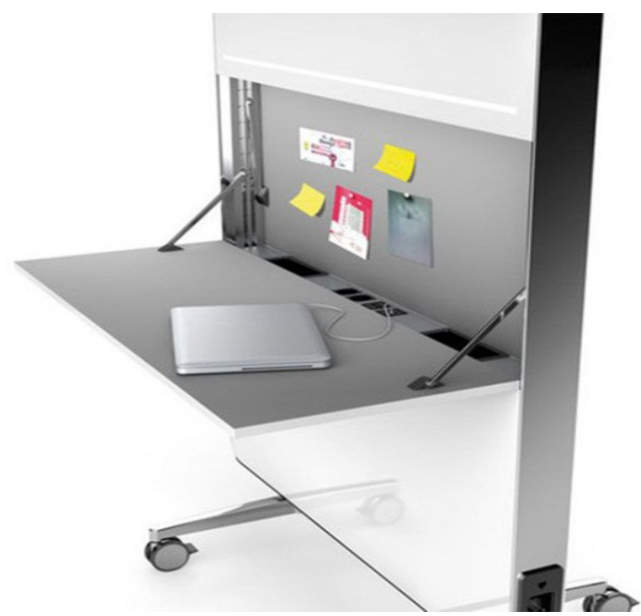

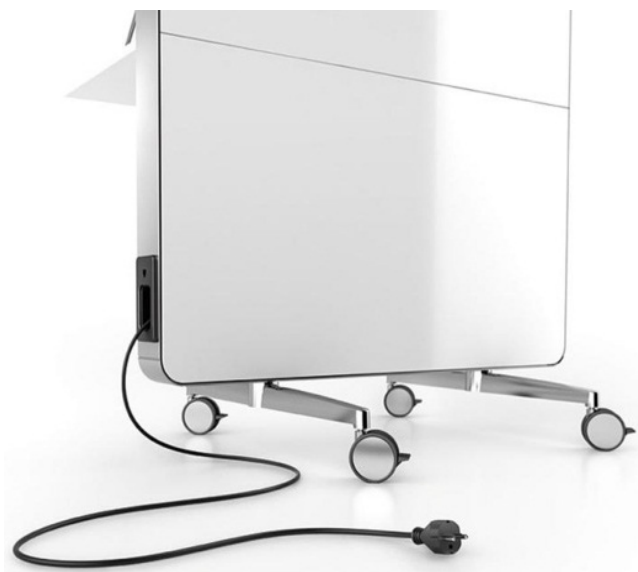

http://ballendat.com/products/mobica/mobica-nomado/

Figure 15. Nomado - Mobica Designer, Martin Ballendat

\section{Conclusions}

The new generation has a different approach to work environment and working culture. People born between the years 1981-2000 grew up with computers, the internet world and cell phones. It is known that the so called 'Y Generation' is not so loyal to constitutions; if they are unhappy, they will change their positions, offices or company fast. So to keep them at the office for long hours is a hard job. The future of office environments should be lively, dynamic; while allowing the staff to work efficiently in the same space. If this is true for the spaces that we work in, we have to ask what makes the workers happy and productive today, what has changed in workspaces and why?

Offices became more collective spaces. For teams or working groups; this approach leads to making designs that enable engaging in the production by being in communication. Ease of communication causes the speed of work to accelerate, so offices are more dynamic spaces now that there is the need to adapt to fast changing organizations or projects. Also, in need, there must be spaces that allow for concentrated working environment because the open planned offices can be distracting for people wanting to focus on the job. Today's offices also integrate socializing areas and give the employees a space to relax. We can see that multi-functional space is required for an efficient and dynamic office today. To make this happen, we need the right furniture that are flexible.

Today's office spaces and furniture designs are made open to innovations in many ways, have adaptive flexibility and are able to respond to the needs of different users. Modular workstations that provide working environment to its user in any direction and any place they want ensure flexibility by supporting changing conditions. The user needs are not only ergonomic or functional needs, but a psychological need to create a personal space within the working environment. Because of this; flexible 
furniture with flexible details for customized or personalized workstations can be seen today to make the workers happy and content.

These systems are a necessity for the changing times that entail new approaches and updates accordingly. With this approach and developments in material, production, communication, information and computer technologies; more ergonomic and flexible furniture are designed. We have given examples of new generation furniture that are storage elements, workstations and partitions. The storage elements have the properties of lightness, so they are portable; changeable in dimensions; and having other functions like being a seating element. Technology is seen to support the flexibility of these products by the usage of composite materials that are both light and strong at the same time.

The workstations have the properties like being transformable to be used personally or by sharing according to the need; and being portable or smaller in size while carrying all the systems integrated in it. The partitions have acoustical properties that are needed in free planned offices. They can be personalized and moved according to the user's need with their different connection details. As we can see from the examples, in flexible offices where the new generation's changing needs and different expectations are supported; lightness, mobility, transformability, acoustics and adaptation to the new technologies are seen as highlights of furniture design.

\section{REFERENCES}

[1] H.Z. Kayan Altınok. Ofis İç Mekan Tasarımlarında Gelişen Teknolojiler Işı̆̆ında Esneklik Ve İstanbul'daki Uygulamalar Üzerinde Analizi, Sanatta Yeterlik Tezi, M.S.G.S.Ü. Fen Bilimleri Enstitüsü, İstanbul, 2011.

[2] Online available from http://www.architectmagazine.com/technology/detail/innov ative-detail-the-superdesk-at-the-barbarian-group-office_o

[3] Online available from http://www.clivewilkinson.com/portfolio page/disney-store -headquarters/
[4] C. Fiell, P. Fiell. Designing the 21st Century, Taschen, Köln, 2005.

[5] Online available from https://abstracta.se/product/collect/

[6] S. Raymond, R. Cunliffe. Tomorrow's Office: Creating Effective and Humane Interiors, E \& FN Spon, 2000.

[7] H.Z. Kayan, B. Köse Khıdırov. Technology Supported Flexible Designs for Furniture Structures, 2nd ICNTAD'16 (2nd International Conference in New Trends in Architecture and Interior Design 2016), Hirvatistan, Zagreb, 19 22.04.2016.

[8] P. Davey. How Has New Technology Affected Furniture Design London, United Kingdom, 2014. Online available from

https://www.behance.net/gallery/13694711/How-Has-NewTechnology-Affected-Furniture-Design

[9] J. Postell. Furniture Design, John Wiley \& Sons Inc., New Jersey, 2007.

[10] D. Bedük. Bilgi Iletişim Çağında Iç Mekan Estetiği, 2. Ulusal Yapı Malzemesi Kongresi Ve Sergisi, ITÜ Taşkışla, İstanbul, 6-8 Ekim 2004.

[11] R. Guidod. Industrial Design Techniques and Materials, Flammarion, 2006.

[12] G.M. Beylerian, A, Dent. Material Connexion, the Global Resource of New and Innovative Materials for Architects, Artists and Designers, Thames \& Hudson Ltd, London, 2005. ISBN-13: 978-0-500-51244-9, ISBN 10: 0-500-51244-2.

[13] K. Schwab. The Fourth Industrial Revolution, Foreign affairs, December 12, 2015. Online available from https://www.foreignaffairs.com/articles/2015-12-12/fourth-i ndustrial-revolution

[14] Online available from http://www.designboom.com/design/alexander-lorenz-kivofurniture-herman-miller-06-18-2014/

[15] Online available from http://www.nendo.jp/en/works/nest-shelf/

[16] Online available from http://www.coroflot.com/davidbruer/Gaia

[17] Online available from https://www.designboom.com/design/benjamin-hubert-layer -design-scale-modular-acoustic-partition-system-12-04-201 $5 /$ 